\title{
Correction to: Sphenoid dysplasia in neurofibromatosis type 1: a new technique for repair
}

\author{
Concezio Di Rocco $^{1}$ - Amir Samii ${ }^{1}$ - Gianpiero Tamburrini ${ }^{2} \cdot$ Luca Massimi $^{2}$. \\ Mario Giordano ${ }^{1}$
}

Published online: 7 October 2017

(C) Springer-Verlag GmbH Germany 2017

Correction to: Childs Nerv Syst (2017) 33:983-986

https://doi.org/10.1007/s00381-017-3408-z

The published version of this article unfortunately contained an error.

All names of the authors have been published incorrectly.

Given in this article are the corrected author names.

The online version of the original article can be found at https://oi.org/ 10.1007/s00381-017-3408-z

\footnotetext{
Mario Giordano giordano.nch@gmail.com

1 Department of Neurosurgery, International Neuroscience Institute, Rudolf Pichlmayr Str. 4, 30625 Hannover, Germany

2 Department of Neurosurgery, Catholic University School of Medicine, Rome, Italy
} 